\title{
Systemic Inflammatory Cytokines Associate With SARS-COV-2 Viral Shedding Time in Covid-19 Inpatients
}

\section{Jing Shi}

Tongji Hospital of Tongji Medical College of Huazhong University of Science and Technology

\section{Chongsheng Cheng}

Tongji Hospital of Tongji Medical College of Huazhong University of Science and Technology

\section{Muqing Yu}

Tongji Hospital of Tongji Medical College of Huazhong University of Science and Technology

\section{Xiaochen Li}

Tongji Hospital of Tongji Medical College of Huazhong University of Science and Technology

\section{Ke Wang}

Tongji Hospital of Tongji Medical College of Huazhong University of Science and Technology

\section{Yu Tao}

Tongji Hospital of Tongji Medical College of Huazhong University of Science and Technology

\section{Ying Zhou}

Tongji Hospital of Tongji Medical College of Huazhong University of Science and Technology

\section{Min Zhou}

Tongji Hospital of Tongji Medical College of Huazhong University of Science and Technology

\section{Shuyun Xu}

Tongji Hospital of Tongji Medical College of Huazhong University of Science and Technology

\section{Lu Qin}

Tongji Hospital of Tongji Medical College of Huazhong University of Science and Technology

\section{Zhenyu Yang}

Tongji Hospital of Tongji Medical College of Huazhong University of Science and Technology

\section{Cong Zhang}

Tongji Hospital of Tongji Medical College of Huazhong University of Science and Technology Junqing Yue

Tongji Hospital of Tongji Medical College of Huazhong University of Science and Technology

\section{Xiansheng Liu}

Tongji Hospital of Tongji Medical College of Huazhong University of Science and Technology

\section{Harald Renz}

Institute of Laboratory Medicine and Pathobiochemistry, Molecular Diagnostics, Philipps University Marburg University Hospital Giessen and Marburg GmbH 
Min Xie ( $\nabla$ xie_m@126.com )

Tongji Hospital of Tongji Medical College of Huazhong University of Science and Technology https://orcid.org/0000-0003-4052-1647

\section{Research}

Keywords: COVID-19, SARS-Cov-2, sIL-2R, viral shedding

Posted Date: May 29th, 2020

DOI: https://doi.org/10.21203/rs.3.rs-31556/v1

License: (c) (1) This work is licensed under a Creative Commons Attribution 4.0 International License. Read Full License 


\section{Abstract}

Background: Since December 2019, coronavirus disease 2019 (COVID-19), as an infectious disease with cytokine storm, has become an emerging global challenge. To assess the duration of SARS-COV-2 viral shedding and associated risk factors in COVID-19 patients.

Methods: COVID-19 patients with interleukin (IL)-1b, soluble interleukin-2 receptor (sIL-2R), IL-6, IL-8, IL-10 and tumor necrosis factor (TNF)-a cytokines data consecutively admitted to Tongji Hospital from January 27, 2020 through February 5, 2020 were enrolled and been followed up until March 24, 2020. We utilized Kaplan-Meier method and Cox proportional hazards regression analysis to assess the duration of viral shedding and risk factors affecting virus clearance.

Results: 246 inpatients with laboratory confirmed COVID-19 were enrolled. The median duration of viral shedding was 24 days, ranging from 6 to 63 days. Age, severity of COVID-19, albumin, lactate dehydrogenase (LDH), D-dimer, ferritin and sIL-2R were associated with duration of viral shedding. Administration of lopinavir-ritonavir, arbidol, oseltamivir and intravenous immunoglobulin did not shorten viral shedding time. Multivariate cox regression analysis revealed that sIL-2R, LDH and severity of COVID19 were independent factors associated with duration of viral shedding. At stratified analysis, the viral shedding time was positively correlated with age, sIL-2R and LDH in non-corticosteroid subgroup, while negatively correlated with lymphocyte count in corticosteroid group.

Conclusions: The present study demonstrated that elevated SIL-2R, increased LDH and severe status were related to prolongation of viral shedding in COVID-19 inpatients. Further research is urgent to investigate the mechanism of immune reaction involved in the virus clearance process and aim to the optimal antiviral therapy.

\section{Introduction}

Coronavirus disease 2019 (COVID-19), caused by the severe acute respiratory syndrome coronavirus 2 (SARS-CoV-2), presents a global challenge. Up to May 4, 2020, more than 3 million confirmed cases of COVID-19 have been reported, of which more than 239,000 have died. ${ }^{1}$ As SARS-CoV-2 is an emerging virus, there is no effective anti-viral drug and vaccine to treat this disease. Supportive therapy is the main pattern. Whether corticosteroids are beneficial or lead to delayed virus shedding remains controversial. Previous studies found that the SARS-CoV-2 persist longer with higher load in severe patients. ${ }^{2}$ Our previous studies found that high cytokine levels, such as soluble interleukin-2 receptor (sIL-2R), interleukin (IL)-6, IL-10 and tumor necrosis factor (TNF)-a were significantly associated with severe COVID-19. ${ }^{3}$ The inflammatory storm caused by SARS-CoV-2 plays an important role in the deterioration of the disease. ${ }^{4}$ However, the association between duration of viral shedding and inflammatory factors was limited.

The assessment of risk factors for delayed virus shedding will benefit the treatment and management of COVID-19. The goal of the present study was to conduct a large population-based study to describe the 
data for duration of viral shedding, and assess the association between duration of viral shedding and relevant characteristics, including age, gender, smoking history, severity of the disease, comorbidities, inflammatory factors and treatment method.

\section{Methods}

\section{Study design and participants}

This study is an observative study of hospitalized patients with COVID-19 enrolled at Sino-French New City Branch of Tongji Hospital, Huazhong University of Science and Technology in Wuhan January 27, 2020 through February 5, 2020. Tongji hospital, HUST is one of the major nationally designated hospitals for COVID-19 in Wuhan. COVID-19 was diagnosed according to WHO interim guidance. ${ }^{5}$ Only the cases with complete cytokines data, including IL-1b, sIL-2R, IL-6, IL-8, IL-10 and TNF-a, were included in the analysis. Patients were divided into severe COVID-19 group and non-severe COVID-19 group according to 2019 clinical practice guideline from IDSA and ATS for diagnosis and treatment of adults with community-acquired pneumonia. ${ }^{6}$ Laboratory confirmed case of COVID-19 was defined as a positive result to next-generation sequencing or real-time reverse-transcriptase polymerase chain reaction assay for nasopharyngeal or pharyngeal swab specimens. ${ }^{7}$ Patients were followed up from the date of admission to March 24, 2020. Viral shedding was defined as SARS-CoV-2 nucleic acid test turned negative for two consecutive times (minimum 24h sampling interval). Duration of viral shedding was defined as the duration from illness onset to the date of first negative result of viral shedding. This study was approved by Institutional Review Board of Tongji Hospital, Huazhong University of Science and Technology. Written informed consent was waived owing to the rapid emergence of this infectious disease.

\section{Data collection}

The demographic data were obtained by face-to-face or telephone interview. Laboratory examination at admission, treatment during hospitalization and outcome data were extracted from electronic medical records. Patient data were cross-checked for consistency before final data entry and then entered into a computerized database.

\section{Statistical analysis}

Continuous variables were expressed as median and interquartile range (IQR). Categorical variables were expressed as number (\%). Survival curves were performed by Kaplan-Meier method and validated by Logrank, Breslow and Tarone-Ware tests. The time-dependent ROC curve analysis was conducted and the area under the curve (AUC) value was used to evaluate the predictive effect of laboratory findings. Adjusted hazard ratios (HRs) along with $95 \%$ confidence intervals (Cls) were calculated by using the Cox proportional hazards regression model. Age, diabetes, lymphocyte count, albumin, sIL-2R and usage of systemic corticosteroids were chosen for multivariate cox regression analysis on the basis of univariate cox regression analysis and clinical significance. The correlation between duration of viral shedding and 
age, sIL-2R, LDH and lymphocyte count was analyzed by Spearman's rank correlation. When the P value was $<0.05$, the difference was regarded as statistically significant. All statistical tests were two tailed. Overall statistical analysis was performed by the software statistical package for social science version 23.0 (SPSS Inc., Chicago, IL, USA) and R software for Windows, version 3.6.1.

\section{Results}

\section{Patient Characteristics}

A total of 246 patients with COVID-19 were enrolled January 27, 2020 through February 5, 2020. Median age of the patients was 58 years (IQR 47-67). 126 (51.2\%) patients were male. 22 (9.0\%) patients were current smokers. 72 (29.3\%) patients had hypertension, 45 (18.3\%) patients had diabetes. 16 (6.5\%) patients had coronary heart disease. 16 (6.5\%) patients had tumor or impaired immune system disease. $14(5.7 \%)$ patients had underlying respiratory disease.

118 (48.0\%) patients were classified as severe cases and 128 (52.0\%) patients were categorized into nonsevere cases. Concentrations of lactate dehydrogenase (LDH) were increased in $163(67.4 \%)$ of 242 patients. $95(40.9 \%)$ of 232 patients had D-dimer over $1 \mathrm{mg} / \mathrm{L}$. Levels of erythrocyte sedimentation rate were increased in 175 (73.5\%) of 238 patients. 201 (82.4\%) of 244 patients had high-sensitive C-reactive protein concentrations greater than $10 \mathrm{mg} / \mathrm{L}$. 20 (9.3\%) of 215 patients had procalcitonin over $0.5 \mathrm{ng} / \mathrm{mL}$. $179(75.5 \%)$ of 237 patients had ferritin levels greater than $400 \mathrm{mg} / \mathrm{L}$. Serum levels of IL-1b, sIL-2R, IL-6, IL-8, IL-10 and TNF-a were increased in $16.7 \%, 52.8 \%, 70.3 \%, 6.5 \%, 28.0 \%$ and $59.3 \%$ patients, respectively.

$113(45.9 \%)$ of 246 patients were treated with low dosage (prednisone-equivalent dose of less than $1 \mathrm{mg} / \mathrm{Kg}$ per day) of systemic corticosteroids, $32(13.0 \%)$ of 246 patients were given high dosage (prednisone-equivalent dose of at least $1 \mathrm{mg} / \mathrm{Kg}$ per day) of systemic corticosteroids. Demographic and clinical characteristics of patients in this study were listed in Table 1 in the Online Repository.

\section{Viral shedding time}

By March 24, 2020, 215 (87.4\%) patients were recorded with the date when the SARS-CoV-2 nucleic acid test turned negative. Two (0.8\%) patients lost follow-up after transferred to other medical centers. 26 $(10.6 \%)$ patients died before the virus turned negative. $2(0.8 \%)$ patients could not have the SARS-CoV-2 nucleic acid test because of their critically ill condition. The mean follow-up period is 53 (49-58) days.

The overall median duration of viral shedding was 24 days. The shortest duration of viral shedding was 6 days from illness onset, whereas the longest one was 63 days. One patient was persistent positive until the end of follow-up date.

By the analysis of Kaplan-Meier method, the severity of disease, old age, low albumin level, high LDH, high D-dimer, high ferritin, high sIL-2R and low lymphocyte count were associated with longer duration of viral shedding time (Table 2, Figure 1). Gender, smoking history, comorbidity, and administration of 
lopinavir-ritonavir, arbidol, oseltamivir and intravenous immunoglobulin were not associated with duration of viral shedding (Table 2).

The median duration of viral shedding was 24 days in patients without systemic corticosteroids, 23 days in patients treated with low dose (prednisone-equivalent dose of less than $1 \mathrm{mg} / \mathrm{Kg}$ per day) and 27 days in patients administrated with high dose (prednisone-equivalent dose of at least $1 \mathrm{mg} / \mathrm{Kg}$ per day) systemic corticosteroids. Low dose of systemic corticosteroids did not prolong viral shedding compared with no use of systemic corticosteroids (Log-rank, $P=0.986$; Breslow, $P=0.677$; Tarone-Ware, $P=0.822$ ). High dose of systemic corticosteroids use may associate with prolonged viral shedding compared with no use of systemic corticosteroids (Log-rank, $P=0.023$; Breslow, $P=0.015$; Tarone-Ware, $P=0.014$ ).

\section{Time-dependent ROC curve analysis}

The time-dependent ROC curve analysis was conducted and the AUC value was used to evaluate the predictive effect of albumin, LDH, D-dimer, ferritin, sIL-2R. As shown in Figure 2, the AUC for albumin was $0.646,0.708$ and 0.665 at 20,40 , and 60 days, respectively; the AUC for LDH was $0.627,0.747$ and 0.762 at 20,40 , and 60 days, respectively; the AUC for D-dimer was $0.648,0.714$ and 0.710 at 20,40 , and 60 days, respectively; the AUC for ferritin was $0.628,0.652$ and 0.683 at 20,40 , and 60 days, respectively; the AUC for sIL-2R was $0.658,0.660$ and 0.710 at 20,40 , and 60 days, respectively.

\section{Univariate and multivariate cox regression analysis}

As shown in Table 3, age, severity of COVID-19, albumin, LDH, D-dimer, ferritin, sIL-2R and administration of high dose systemic corticosteroids were significantly associated with duration of viral shedding in univariate cox regression analysis $(P<0.05)$. Ten variables, including age, severity of COVID-19, diabetes, lymphocyte count, albumin, LDH, D-dimer, ferritin, sIL-2R and usage of systemic corticosteroids were chosen in multivariate cox regression analysis on the basis of univariate cox regression analysis and clinical significance. In the final model, sIL-2R, LDH and severity of COVID-19 were independent factors associated with duration of viral shedding. sIL-2R $>710 \mathrm{U} / \mathrm{mL}(\mathrm{HR}=0.719 ; P=0.031 ; 95 \% \mathrm{Cl} 0.533-0.971)$, $\mathrm{LDH}>250 \mathrm{U} / \mathrm{L}(\mathrm{HR}=0.691 ; P=0.022 ; 95 \% \mathrm{Cl} 0.503-0.949)$ and severe status of COVID-19 (HR=0.712; $P=0.032 ; 95 \% \mathrm{Cl} 0.522-0.971$ ) were related to prolongation of viral shedding (Table 3 ).

\section{Stratified analysis}

According to whether systemic corticosteroid was used, the correlation between duration of viral shedding and age, sIL-2R, LDH and lymphocyte count was stratified analyzed. As shown in Figure 3, when systemic corticosteroid was not used, duration of viral shedding was positively correlated with age $\left(r_{\mathrm{s}}=0.316, P=0.002\right)$, slL-2R $\left(\mathrm{r}_{\mathrm{s}}=0.259, P=0.012\right)$ and LDH $\left(\mathrm{r}_{\mathrm{s}}=0.290, P=0.005\right)$, but not lymphocyte count $\left(r_{s}=-0.069, P=0.508\right)$. When systemic corticosteroid was used, duration of viral shedding was positively correlated with sIL-2R $\left(r_{s}=0.193, P=0.033\right)$ and negatively with lymphocyte count $\left(r_{s}=-0.184, P=0.044\right)$, but not age $\left(r_{s}=-0.034, P=0.714\right)$ and $\operatorname{LH}\left(r_{s}=0.165, P=0.074\right)$. 


\section{Discussion}

Little do we know about the duration of viral shedding of COVID-19, a novel infectious disease. As far as we know, this study proposed the longest follow-up duration of the viral shedding in COVID-19. Our result revealed that the viral shedding time ranged from 6 to 63 days, which was wider than previous study in Wuhan with a range of 8 to 37 days $^{8}$ and another study performed in Shanghai with a range of 2 to 22 days. ${ }^{9}$ The longer duration of viral shedding time in this study may result from a higher severity of the patients recruited in Tongji hospital and a longer duration of follow-up time.

In univariate cox regression analysis, age was significantly associated with duration of viral shedding. Elderly patients experience a marked decline of immune function. The age-dependent defects in T-cell and B-cell function and the excess production of type 2 cytokines could lead to a deficiency in control of viral replication. ${ }^{8,10}$ Diabetes was the most common comorbidity in elderly patients with COVID-19. Previous study found that COVID-19 patients with diabetes were at higher risk of severe pneumonia, release of tissue injury-related enzymes, excessive uncontrolled inflammation response, hypercoagulable state and rapid deterioration. ${ }^{11}$ However, there was no difference in viral shedding time between patients with or without diabetes in our study. Larger sample studies are needed to explore virus clearance ability of patients with diabetes. In the present study, although the $P$ value of Log-rank test is greater than 0.05 , but the $P$ values of Breslow and Tarone-Ware tests were less than 0.05 , lymphocyte count $<0.5 \times 10^{9} / \mathrm{L}$ may be associated with delayed virus shedding. Lymphocytes play a crucial role in immune system. Lymphopenia was commonly observed in severe COVID-19 illness. ${ }^{8}$ Analyze of lymphocyte subsets demonstrated that absolute numbers of $T$ lymphocytes, $C D 4+$ and $C D 8+T$ cells decrease in nearly all the patients, and were markedly lower in severe cases. ${ }^{12}$

Corticosteroids could suppress cytokine storm of COVID-19, but also inhibit immune response and holds the possibility to delay viral clearance. In severe acute respiratory syndrome and Middle East respiratory syndrome, corticosteroids were not routinely recommended. ${ }^{13}$ Whether corticosteroids are beneficial or lead to poor clinical outcomes in COVID-19 remains controversial. Our study revealed that for the comparison between high dose systemic corticosteroids and no use of systemic corticosteroids, although the $P$ value of Log-rank test is greater than 0.017 , the $P$ values of Breslow and Tarone-Ware tests were less than 0.017 . High dose systemic corticosteroids may associate with prolonged viral shedding compared with no use of systemic corticosteroid. This may due to the impaired immune response aggravated by high-dose systemic corticosteroids, but also could be an indicator of severe condition when high dose corticosteroid would be used. Further research is needed to clarify the role of systemic corticosteroid in viral shedding of COVID-19. The present study also identified that administration of lopinavir-ritonavir did not shorten viral shedding time (Log Rank, $P>0.05$; Breslow, P>0.05; Tarone-Ware, $P>0.05)$. Our result was consistent with previous clinical trial that the percentage of patients with detectable viral RNA for SARS-CoV-2 at various time points were similar between the lopinavir-ritonavir group and the standard-care group. ${ }^{14}$ Oseltamivir is an antiviral used to treat influenza virus. December and January were the high incidence period of influenza in Wuhan previously. Co-infected with influenza 
virus was likely existed in COVID-19 patients. Although oseltamivir was prescribed to $39 \%$ patients, our result showed that oseltamivir did not affect duration of viral shedding. Thus, we speculate that the seasonal influenza may not affect the viral shedding of SARS-Cov-2. Arbidol is a broad-spectrum antiviral, which can inhibit numerous enveloped or non-enveloped RNA or DNA viruses. Previous study showed arbidol treatment potentially improved discharging rate and decrease the mortality rate of COVID19. ${ }^{15}$ While, this study indicated that arbidol did not shorten duration of viral shedding. High quality clinical research is needed to verify the clinical efficacy of arbidol on COVID-19 patients.

In our study, virus shedding was delay in severe patients. Previous study suggests high viral load is associated with COVID-19 severity. ${ }^{16}$ The increased viral load may contribute to the longer viral shedding in severe cases of COVID-19. The other reason may due to the impaired immune since the severe COVID patients presented with significantly decreased lymphocyte. In previous studies, continuously decrease of serum albumin is observed in critical cases, which was associated with poor clinical outcome in hospitalized patients. ${ }^{17}$ Albumin can reflect the basic nutrition status. Over consumption of COVID-19 and inadequate nutrition intake may lead to hypoalbuminemia. This study demonstrated low level albumin associated with delayed viral shedding in consistent with previous study finding that albumin level was significantly correlated with SARS-CoV-2 viral load. ${ }^{16}$ Therefore, nutrition support is very important in the healthcare of COVID-19. LDH was a glycolytic enzyme, which widely exist in many organs and tissues, especially in fast growing tumors. LDH was often regarded as an indicator of organ injury and tumor burden. ${ }^{18}$ Previous studies found that high level LDH were common in severe cases and correlated with severe acute lung injury. ${ }^{12,16}$ The present study revealed that high level LDH was associated with prolongation of viral shedding time, which may be due to the severe lung injury. Our study also found that elevated D-dimer level was associated with delayed viral shedding. Serum D-dimer can reflect fibrinolytic activities and was also an inflammatory biomarker. ${ }^{19}$ Previous studies found that severe cases were commonly complicated with coagulopathy, markedly elevated D-dimer was related to poor prognosis of severe COVID-19. ${ }^{20}$

Inflammatory cytokines would be highly associated with severity and immune status of COVID-19. The present study indicated that increased levels of ferritin and SIL-2R were related to prolongation of viral shedding time. Hyperferritin, a marker of macrophage activation, reflect the activation of reticuloendothelial system. ${ }^{21}$ As an acute-phase reactant, ferritin level can be used as an indicator to reflect the degree of inflammation of inpatients with COVID-19. IL-2R is composed of three subunits: $a, b$, and $g_{c}$. While $b$ and $g_{c}$ subunits are constitutively active, the a subunit is induced and expressed only after mononuclear cell activation. ${ }^{22,23}$ The sIL-2R is generated in "activation-dependent" manner, it is cleaved from IL-2Ra protein once T cells are activated. ${ }^{22,23}$ Therefore, sIL-2R is used as a classical hallmark of $\mathrm{T}$ cell activation. ${ }^{23}$ It can also be released from activated $\mathrm{B}$ cells, monocytes and dendritic cells. ${ }^{23}$ Significant increase of sIL-2R are seen in autoimmune disease, organ transplant rejection and in many $T$ cell and B cell neoplasms. ${ }^{24}$ In autoimmune disease, sIL-2R level associated with disease activity and reflects immune system activation. ${ }^{25}$ In clinic, sIL-2R is also an important diagnostic and disease 
marker in hemophagocytic syndromes/hemophagocytic (HPS/HLH). ${ }^{22,23}$ High levels of sIL-2R are associated with poor prognosis, and falling sIL-2R corresponds to disease remission or treatment response in $\mathrm{HPS} / \mathrm{HLH} .{ }^{23} \mathrm{~A}$ cytokine profile resembling secondary hemophagocytic lymphohistiocytosis (sHLH) was seem in COVID-19. ${ }^{26}$ sIL-2R can be used as a biomarker of immune system activation in patients with COVID-19 and predict the prognosis of COVID-19.

The duration of viral shedding was correlated with viral load, host immune response and treatment. Administration of systemic corticosteroid may impair immune response and delay viral clearance. When systemic corticosteroid was not used, the duration of viral shedding was correlated with age. The viral shedding time was longer in elder patients. However, when systemic corticosteroid was used, the duration of viral shedding was not correlated with age. Similarly, the duration of viral shedding was correlated with LDH when systemic corticosteroid was not used. The viral shedding time was longer in patients with elevated LDH. But when systemic corticosteroid was uses, the predict effect of LDH disappeared due to the impairment of systemic corticosteroid. When systemic corticosteroid was not used, the duration of viral shedding was not correlated with lymphocyte count. In cases administrated with systemic corticosteroid, the duration of viral shedding was negatively correlated with lymphocyte count. This may because high dose corticosteroid would be used in severe cases, in whom lymphopenia was very common, and viral shedding time was longer. sIL-2R was positively associated with duration of viral shedding no matter whether systemic corticosteroid was used or not. The result suggests that sIL-2R was an independent factor for predicting viral shedding time. It is a key factor for the virus inducing immune reaction in COVID-19 patients. The delayed viral shedding may associate with high virus load which stimulates the IL-2R related immune activation.

To our knowledge, this is the most detailed study of duration of viral shedding and its association with cytokines in COVID-19 patients. However, there are some limitations to this study. Firstly, there was potential false negative in SARS-CoV-2 nucleic acid test. Secondly, due to limited medical resources during the outbreak, only patients with severe symptoms could be admitted to hospital and most patients were severe cases. The durations of viral shedding from illness onset in this study tended to be very long and may differ from those in all population of COVID-19 patients. Duration of viral shedding in asymptomatic patients need to be further investigated. Finally, this report is a descriptive study, further research is urgent to investigate the mechanism of immune reaction involved in the virus clearance process.

\section{Conclusions}

The median duration of viral shedding was 24 days. Low dose of systemic corticosteroids did not prolong viral shedding compared with no use of systemic corticosteroids. The current antiviral treatments including lopinavir-ritonavir, arbidol, oseltamivir and intravenous immunoglobulin did not shorten viral shedding time. sIL-2R $>710 \mathrm{U} / \mathrm{mL}, \mathrm{LDH}>250 \mathrm{U} / \mathrm{L}$ and severe COVID-19 were related to prolongation of viral shedding. Optimal antiviral treatment strategy is urgently needed in the future. 


\section{Abbreviations}

COVID-19: Coronavirus disease 2019; IL: Interleukin; sIL-2R: Soluble interleukin-2 receptor; TNF: Tumor necrosis factor; LDH: Lactate dehydrogenase; SARS-CoV-2: Severe acute respiratory syndrome coronavirus 2; IQR: Interquartile range; AUC: Area under the curve; HRs: Hazard ratios; Cls: Confidence intervals; HPS/HLH: Hemophagocytic syndromes/hemophagocytic; sHLH: Secondary hemophagocytic lymphohistiocytosis

\section{Declarations}

\section{Acknowledgments}

We respectfully and sincerely thank all front-line medical staff for hard work and sacrifice.

\section{Authors' Contributions}

$M X, S X$ and $M Z$ conceived and designed the study. JS and MX contributed to the literature search and writing of the report. MY, KW, YT, YZ, LQ and JS contributed to data collection. JS, XLi, MX, HR, ZY, CZ, JY and CC contributed to data analysis and data interpretation. XLiu, HR and MX contributed to revision of the manuscript. ${ }^{*}$ Contributed equally.

\section{Funding}

This research did not receive any specific grant from funding agencies in the public, commercial, or notfor-profit sectors.

\section{Availability of data and materials}

The datasets used and/or analyzed during the current study are available from the corresponding author on reasonable request.

\section{Ethics approval and consent to participate}

This study was approved by the Ethics Commission of Tongji Hospital (TJ-C20200122).

\section{Consent for publication}

Not applicable.

\section{Competing interests}

HR is member of and receives funding from the German Lung Centre (DZL) and of the Universities Giessen and Marburg Lung Centre (UGMLC). The other authors declare that they have no competing interests. 


\section{Author details}

${ }^{1}$ Department of Respiratory and Critical Care Medicine, Tongji Hospital, Tongji Medical College, Huazhong University of Science and Technology, Wuhan, China. ${ }^{2}$ Key Laboratory of Respiratory Diseases, National Ministry of Health of the People's Republic of China and National Clinical Research Center for Respiratory Disease, Wuhan, China. ${ }^{3}$ Institute of Laboratory Medicine and Pathobiochemistry, Molecular Diagnostics, Philipps University Marburg University Hospital Giessen and Marburg GmbH

\section{References}

1 WHO. Coronavirus Disease 2019 (COVID-19) Situation report-105. May 4, 2020. https://www.who.int/docs/default-source/coronaviruse/situation-reports/20200504-covid-19-sitrep105.pdf?sfvrsn=4cdda8af_2 (accessed May 5, 2020).

2 Zheng S, Fan J, Yu F, Feng B, Lou B, Zou Q, et al. Viral load dynamics and disease severity in patients infected with SARS-CoV-2 in Zhejiang province, China, January-March 2020: retrospective cohort study. BMJ 2020;369:m1443.

3 Li X, Xu S, Yu M, Wang K, Tao Y, Zhou Y, et al. Risk factors for severity and mortality in adult COVID19 inpatients in Wuhan. J Allergy Clin Immunol 2020; pii: S0091-6749(20)30495-4.

4 Ye Q, Wang B, Mao J. The pathogenesis and treatment of the 'Cytokine Storm' in COVID-19. J Infect 2020; pii: S0163-4453(20)30165-1.

5 WHO. Clinical management of severe acute respiratory infection when Novel coronavirus (nCoV) infection is suspected. Jan 11, 2020. https://www.who.int/internal-publications-detail/clinicalmanagement-of-severe-acute-respiratory-infection-when-novel-coronavirus-(ncov)-infection-is-suspected (accessed Jan 19, 2020).

6 Metlay JP, Waterer GW, Long AC, Anzueto A, Brozek J, Crothers K, et al. Diagnosis and Treatment of Adults with Community-acquired Pneumonia. An Official Clinical Practice Guideline of the American Thoracic Society and Infectious Diseases Society of America. Am J Respir Crit Care Med 2019; 200: e45e67.

7 WHO. Laboratory testing for 2019 novel coronavirus (2019-nCoV) in suspected human cases. March 19, 2020. https://www.who.int/publications-detail/laboratory-testing-for-2019-novel-coronavirus-insuspected-human-cases-20200117 (accessed Mar 20, 2020).

8 Zhou F, Yu T, Du R, Fan G, Liu Y, Liu Z, et al. Clinical course and risk factors for mortality of adult inpatients with COVID-19 in Wuhan, China: a retrospective cohort study. Lancet 2020; 395: 1054-62.

9 Ling Y, Xu SB, Lin YX, Tian D, Zhu ZQ, Dai FH, et al. Persistence and clearance of viral RNA in 2019 novel coronavirus disease rehabilitation patients. Chin Med J (Engl). 2020 Feb 28. doi: 
10 Opal SM, Girard TD, Ely EW. The immunopathogenesis of sepsis in elderly patients. Clin Infect Dis 2005; 41 Suppl 7: S504-12.

11 Guo W, Li M, Dong Y, Zhou H, Zhang Z, Tian C, et al. Diabetes is a risk factor for the progression and prognosis of COVID-19. Diabetes Metab Res Rev 2020; e3319.

12 Chen G, Wu D, Guo W, Cao Y, Huang D, Wang H, et al. Clinical and immunological features of severe and moderate coronavirus disease 2019. J Clin Invest 2020; pii: 137244.

13 Russell CD, Millar JE, Baillie JK. Clinical evidence does not support corticosteroid treatment for 2019nCoV lung injury. Lancet 2020; 395: 473-5.

14 Cao B, Wang Y, Wen D, Liu W, Wang J, Fan G, et al. A Trial of Lopinavir-Ritonavir in Adults Hospitalized with Severe Covid-19. N Engl J Med 2020; published online Mar 18.

DOI:10.1056/NEJMoa2001282.

15 Wang Z, Yang B, Li Q, Wen L, Zhang R. Clinical Features of 69 Cases with Coronavirus Disease 2019 in Wuhan, China. Clin Infect Dis 2020; pii: ciaa272.

16 Liu Y, Yang Y, Zhang C, Huang F, Wang F, Yuan J, et al. Clinical and biochemical indexes from 2019nCoV infected patients linked to viral loads and lung injury. Sci China Life Sci 2020; 63: 364-74.

17 Zhang Y, Zheng L, Liu L, Zhao M, Xiao J, Zhao Q. Liver impairment in COVID-19 patients: a retrospective analysis of 115 cases from a single center in Wuhan city, China. Liver Int 2020; published online Apr 2. DOI:10.1111/liv.14455.

18 Zhao Y, Lu D, Ma S, Li L, Zhu J, Zhou, et al. Risk factors of early death in adult patients with secondary hemophagocytic lymphohistiocytosis: a single-institution study of 171 Chinese patients. Hematology 2019; 24: 606-12.

19 Xiong L, Li S, Dai M. Comparison of D-dimer with CRP and ESR for diagnosis of periprosthetic joint infection. J Orthop Surg Res 2019; 14: 240.

20 Yin S, Huang M, Li D, Tang N. Difference of coagulation features between severe pneumonia induced by SARS-CoV2 and non-SARS-CoV2. J Thromb Thrombolysis 2020; published online Apr 3. DOI: 10.1007/s11239-020-02105-8.

21 Kernan KF, Carcillo JA. Hyperferritinemia and inflammation. Int Immunol 2017; 29(9): 401-9.

22 Rubin LA, Nelson DL. The soluble interleukin-2 receptor: biology, function, and clinical application. Ann Intern Med 1990; 113(8): 619-27. 
23 Lin M, Park S, Hayden A, Giustini D, Trinkaus M, Pudek M, et al. Clinical utility of soluble interleukin-2 receptor in hemophagocytic syndromes: a systematic scoping review. Ann Hematol 2017; 96: 1241-51.

24 Morris JC, Waldmann TA. Advances in interleukin 2 receptor targeted treatment. Ann Rheum Dis 2000; 59 Suppl 1: i109-14.

25 Chrobák L. Clinical significance of soluble interleukin-2 receptor. Acta Medica (Hradec Kralove) 1996; 39: 3-6.

26 Mehta P, McAuley DF, Brown M, Sanchez E, Tattersall RS, Manson JJ, et al. COVID-19: consider cytokine storm syndromes and immunosuppression. Lancet 2020; 395: 1033-4.

\section{Tables}

Table 1: Demographic and clinical characteristics of inpatients with COVID-19 


\begin{tabular}{|c|c|}
\hline Factors & Values \\
\hline Age, years & $58.0(47.0-67.0)$ \\
\hline$<60$ & $136 / 246(55.3 \%)$ \\
\hline$\geq 60$ & $110 / 246(44.7 \%)$ \\
\hline \multicolumn{2}{|l|}{ Sex } \\
\hline Female & $120 / 246(48.8 \%)$ \\
\hline Male & $126 / 246(51.2 \%)$ \\
\hline \multicolumn{2}{|l|}{ Smoking history } \\
\hline Never smokers & $205 / 245(83.7 \%)$ \\
\hline Former smokers & $18 / 245(7.3 \%)$ \\
\hline Current smokers & $22 / 245(9.0 \%)$ \\
\hline \multicolumn{2}{|l|}{ Severity of COVID-19 } \\
\hline Non-severe & $128 / 246(52.0 \%)$ \\
\hline Severe & $118 / 246(48.0 \%)$ \\
\hline \multicolumn{2}{|l|}{ Comorbidity } \\
\hline Respiratory diseases & $14 / 246(5.7 \%)$ \\
\hline Diabetes & $45 / 246(18.3 \%)$ \\
\hline Hypertension & $72 / 246(29.3 \%)$ \\
\hline Coronary heart disease & $16 / 246(6.5 \%)$ \\
\hline Tumor or impaired immune system disease & $16 / 246(6.5 \%)$ \\
\hline Blood leukocyte count, $\times 10 \square / L$ & $5.2(3.9-6.8)$ \\
\hline$£ 10$ & $229 / 244(93.9 \%)$ \\
\hline$>10$ & $15 / 244(6.1 \%)$ \\
\hline Neutrophil count, $\times 10 \square / L$ & $3.8(2.6-5.3)$ \\
\hline$£ 7.5$ & $218 / 244(89.3 \%)$ \\
\hline$>7.5$ & $26 / 244(10.7 \%)$ \\
\hline Lymphocyte count, $\times 10 \square / L$ & $0.9(0.6-1.1)$ \\
\hline$\square 0.5$ & $219 / 244(89.8 \%)$ \\
\hline$<0.5$ & $25 / 244(10.2 \%)$ \\
\hline Globulin, g/L & $33.5(30.7-36.8)$ \\
\hline$£ 35$ & $158 / 244(64.8 \%)$ \\
\hline$>35$ & $86 / 244(35.2 \%)$ \\
\hline Albumin, $g / L$ & $34.1(31.4-37.2)$ \\
\hline$\square 35$ & $104 / 245(42.4 \%)$ \\
\hline$<35$ & $141 / 245(57.6 \%)$ \\
\hline Lactose dehydrogenase, U/L & $298.5(234.8-426.5)$ \\
\hline
\end{tabular}

Page 14/24 


$£ 250$
$>250$
Creatinine, $\mu \mathrm{mol} / \mathrm{L}$
$£ 133$
$>133$
D-dimer, mg/L
$£ 1$
$>1$
Erythrocyte sedimentation rate, $\mathrm{mm} / \mathrm{h}$
$£ 20$
$>20$
High-sensitive C-reactive protein, mg/L
$£ 10$
$>10$
Procalcitonin, ng/mL
$£ 0.5$
$\quad 0.5$
$\quad$

Ferritin, $\mu \mathrm{g} / \mathrm{L}$

$£ 400$

$>400$

IL-1 $\beta, \mathrm{ng} / \mathrm{L}$

£5

$>5$

sIL-2R, U/mL

$£ 710$

$>710$

IL-6, ng/L

£7

$>7$

IL-8, ng/L

$£ 62$

$>62$

IL-10, ng/L

$£ 9.1$

$>9.1$

TNF- $\alpha, n g / L$
79/242 (32.6\%)

$163 / 242(67.4 \%)$

68.0 (55.0-88.5)

233/244 (95.5\%)

$11 / 244(4.5 \%)$

$0.8(0.5-1.7)$

137/232 (59.1\%)

95/232 (40.9\%)

35.0 (20.0-58.0)

63/238 (26.5\%)

175/238 (73.5\%)

$44.6(16.2-86.5)$

43/244 (17.6\%)

201/244 (82.4\%)

$0.1(0-0.2)$

195/215 (90.7\%)

$20 / 215(9.3 \%)$

651.8 (418.3-1282.9)

$58 / 237(24.5 \%)$

179/237 (75.5\%)

$5.0(5.0-5.0)$

205/246 (83.3\%)

$41 / 246$ (16.7\%)

744.5 (531.3-1035.0)

116/246 (47.2\%)

130/246 (52.8\%)

$19.6(5.3-47.4)$

73/246 (29.7\%)

173/246 (70.3\%)

$16.3(10.3-24.7)$

230/246 (93.5\%)

$16 / 246(6.5 \%)$

5.4 (5.0-10.0)

177/246 (72.0\%)

69/246 (28.0\%)

$8.9(7.1-11.1)$ 
$€ 8.1$

$>8.1$

Systemic corticosteroids

Duration, days

Prednisone-equivalent dose, mg/Kg per day

0

$<1$

$\square 1$

Intravenous immunoglobulin

Lopinavir-ritonavir

Arbidol

Oseltamivir
$100 / 246(40.7 \%)$

$146 / 246(59.3 \%)$

$4.0(0-10.3)$

$101 / 246(41.1 \%)$

$113 / 246(45.9 \%)$

$32 / 246(13.0 \%)$

$94 / 245(38.4 \%)$

$74 / 246(30.1 \%)$

$182 / 246(74.0 \%)$

$96 / 246(39.0 \%)$

$\mathrm{IL}=$ interleukin. $\mathrm{TNF}=$ tumor necrosis factor. Data are expressed as median (IQR), $\mathrm{n} / \mathrm{N}$ (\%), where $\mathrm{N}$ is the total number of patients with available data.

Table 2: Median duration of viral shedding in patients with COVID-19 


\begin{tabular}{|c|c|c|c|c|}
\hline Factors & & Median duration of viral shedding & $95 \% \mathrm{CI}$ & $\begin{array}{c}P \text { value } \\
\text { (Log-rank) }\end{array}$ \\
\hline \multirow[t]{2}{*}{ Age, years } & $<60$ & 23 & $21.6-24.4$ & 0.011 \\
\hline & $\geq 60$ & 27 & $25.2-28.8$ & \\
\hline \multirow[t]{2}{*}{ Sex } & Female & 25 & $22.7-27.3$ & 0.247 \\
\hline & Male & 23 & $21.7-24.3$ & \\
\hline \multirow[t]{3}{*}{ Smoking history } & Never smokers & 24 & $22.4-25.6$ & 0.823 \\
\hline & Former smokers & 22 & $20.8-23.2$ & \\
\hline & Current smokers & 23 & $17.9-28.1$ & \\
\hline \multirow[t]{2}{*}{ Severity of COVID-19 } & Non-severe & 22 & $20.8-23.2$ & $<0.001$ \\
\hline & Severe & 27 & $25.9-28.1$ & \\
\hline \multicolumn{5}{|l|}{ Comorbidity } \\
\hline \multirow[t]{2}{*}{ Respiratory diseases } & Without & 24 & $22.4-25.6$ & 0.735 \\
\hline & With & 27 & 18.9-35.1 & \\
\hline \multirow[t]{2}{*}{ Diabetes } & Without & 24 & $22.4-25.6$ & 0.716 \\
\hline & With & 24 & $19.3-28.7$ & \\
\hline \multirow[t]{2}{*}{ Hypertension } & Without & 23 & 21.4-24.6 & 0.613 \\
\hline & With & 25 & $21.0-29.0$ & \\
\hline \multirow[t]{2}{*}{ Coronary heart disease } & Without & 24 & $22.4-25.6$ & 0.327 \\
\hline & With & 22 & 20.4-23.6 & \\
\hline \multirow[t]{2}{*}{ Tumor or impaired immune system disease } & Without & 24 & $22.3-25.7$ & 0.565 \\
\hline & With & 23 & $20.4-25.6$ & \\
\hline \multicolumn{5}{|l|}{ Blood leukocyte count, $\times 10 \square / L$} \\
\hline & $£ 10$ & 24 & $22.5-25.5$ & 0.436 \\
\hline & $>10$ & 27 & 19.9-34.1 & \\
\hline \multicolumn{5}{|l|}{ Neutrophil count, $\times 10 \square / \mathrm{L}$} \\
\hline & $£ 7.5$ & 23 & $21.5-24.5$ & 0.332 \\
\hline & $>7.5$ & 28 & 25.5-30.5 & \\
\hline \multicolumn{5}{|l|}{ Lymphocyte count, $\times 10 \square / L$} \\
\hline & $\square 0.5$ & 23 & $21.7-24.3$ & 0.067 \\
\hline & $<0.5$ & 28 & $24.7-31.3$ & \\
\hline \multicolumn{5}{|l|}{ Globulin, g/L } \\
\hline & $£ 35$ & 23 & $21.7-24.3$ & 0.240 \\
\hline & $>35$ & 26 & $24.2-27.8$ & \\
\hline \multicolumn{5}{|l|}{ Albumin, g/L } \\
\hline & $\square 35$ & 22 & $20.3-23.7$ & 0.017 \\
\hline & $<35$ & 25 & $23.1-26.9$ & \\
\hline
\end{tabular}

Page 17/24 
Lactose dehydrogenase, U/L

$£ 250$

$>250$

Creatinine, $\mu \mathrm{mol} / \mathrm{L}$

$£ 133$

$>133$

D-dimer, mg/ L

£1

$>1$

Erythrocyte sedimentation rate, $\mathrm{mm} / \mathrm{h}$
Procalcitonin, ng/mL
23

24

High-sensitive C-reactive protein, mg/L
IL-1 $\beta, \mathrm{ng} / \mathrm{L}$
£5

$>5$

sIL-2R, U/mL
$£ 400$

$>400$
22

24

23

25

22

26
20.7-23.3

25.5-28.6

21.0-25.0

0.278

22.3-25.7

18.3-25.7

22.5-25.5

21.4-24.6

0.258

22.0-30.0

19.2-22.8

0.017

23.2-26.8

21.4-24.6

0.998

21.4-28.6

20.8-23.2 0.002

24.5-27.5

IL-6, ng/L
£7

$>7$

IL-8, ng/L
$22.0-26.0$
21.5-24.5

0.405
21.7-32.3

IL-10, ng/L

21.5-24.5 0.347

23.5-28.6 
TNF- $\alpha, n g / L$

$\begin{array}{llll}£ 8.1 & 25 & 22.7-27.3 & 0.522 \\ >8.1 & 23 & 21.5-24.5 & \end{array}$

Systemic corticosteroids

Prednisone-equivalent dose, $\mathrm{mg} / \mathrm{Kg}$ per day $\quad 0$

$<1$

$\square 1$

Intravenous immunoglobulin

No

Yes

Lopinavir-ritonavir

No

Yes

No

Yes

Oseltamivir

No

Yes
24

23

27

23

24

23

25

22

24

25

23
21.9-26.1 $\quad 0.046$

21.4-24.6

19.2-34.8

21.3-24.7 $\quad 0.477$

21.8-26.2

21.2-24.8

0.553

22.3-27.7

19.9-24.1

0.628

22.3-25.7

22.3-27.7

0.088

21.6-24.4

$\mathrm{CI}=$ confidence interval. $\mathrm{IL}=$ interleukin. $\mathrm{TNF}=$ tumor necrosis factor. The Kaplan-Meier method was used to calculate the median duration of viral shedding and validated by Log-rank test.

Table 3: Cox regression analysis of clinical characteristics associated with viral shedding duration in patients with COVID-19 


\begin{tabular}{|c|c|c|c|c|c|}
\hline Variable & & $\begin{array}{l}\text { Univariate } \\
\text { HR }(95 \% \mathrm{CI})\end{array}$ & $P$ value & $\begin{array}{l}\text { Multivariate } \\
\text { HR }(95 \% \mathrm{CI})\end{array}$ & $P$ value \\
\hline \multirow[t]{2}{*}{ Age, years } & $<60$ & Ref & & & \\
\hline & $\geq 60$ & $0.713(0.543-0.938)$ & 0.016 & & \\
\hline \multirow[t]{2}{*}{ Sex } & Female & Ref & & & \\
\hline & Male & 1.165 (0.889-1.528) & 0.268 & & \\
\hline \multirow[t]{3}{*}{ Smoking history } & Never smokers & Ref & & & \\
\hline & Former smokers & $1.094(0.644-1.857)$ & 0.740 & & \\
\hline & Current smokers & $0.894(0.557-1.435)$ & 0.642 & & \\
\hline \multirow[t]{2}{*}{ Severity of COVID-19 } & Non-severe & Ref & & Ref & \\
\hline & Severe & $0.612(0.465-0.806)$ & $<0.001$ & $0.712(0.522-0.971)$ & 0.032 \\
\hline \multicolumn{6}{|l|}{ Comorbidity } \\
\hline \multirow[t]{2}{*}{ Respiratory diseases } & Without & Ref & & & \\
\hline & With & 1.101 (0.614-1.977) & 0.746 & & \\
\hline \multirow[t]{2}{*}{ Diabetes } & Without & Ref & & & \\
\hline & With & $0.937(0.648-1.354)$ & 0.728 & & \\
\hline \multirow[t]{2}{*}{ Hypertension } & Without & Ref & & & \\
\hline & With & $0.927(0.683-1.259)$ & 0.628 & & \\
\hline \multirow[t]{2}{*}{ Coronary heart disease } & Without & Ref & & & \\
\hline & With & 1.309 (0.746-2.298) & 0.348 & & \\
\hline \multirow[t]{2}{*}{ Tumor or impaired immune system disease } & Without & Ref & & & \\
\hline & With & $1.166(0.677-2.007)$ & 0.581 & & \\
\hline \multirow[t]{2}{*}{ Blood leukocyte count, $\times 10 \square / \mathrm{L}$} & $\leq 10$ & Ref & & & \\
\hline & $>10$ & $0.785(0.415-1.484)$ & 0.456 & & \\
\hline \multirow[t]{2}{*}{ Neutrophil count, $\times 10 \square / L$} & $\leq 7.5$ & Ref & & & \\
\hline & $>7.5$ & $0.785(0.471-1.308)$ & 0.353 & & \\
\hline \multirow[t]{2}{*}{ Lymphocyte count, $\times 10 \square / \mathrm{L}$} & $\leq 0.5$ & Ref & & & \\
\hline & $>0.5$ & $0.651(0.401-1.056)$ & 0.082 & & \\
\hline \multirow[t]{2}{*}{ Globulin, $\mathrm{g} / \mathrm{L}$} & $\leq 35$ & Ref & & & \\
\hline & $>35$ & $0.849(0.638-1.130)$ & 0.263 & & \\
\hline \multirow[t]{2}{*}{ Albumin, $\mathrm{g} / \mathrm{L}$} & $\square 35$ & Ref & & & \\
\hline & $<35$ & $0.729(0.555-0.958)$ & 0.023 & & \\
\hline \multirow[t]{2}{*}{ Lactose dehydrogenase, U/L } & $\leq 250$ & Ref & & Ref & \\
\hline & $>250$ & $0.634(0.476-0.843)$ & 0.002 & $0.691(0.503-0.949)$ & 0.022 \\
\hline \multirow[t]{2}{*}{ Creatinine, $\mu \mathrm{mol} / \mathrm{L}$} & $\leq 133$ & Ref & & & \\
\hline & $>133$ & 1.470 (0.689-3.138) & 0.319 & & \\
\hline D-dimer, mg/L & $\leq 1$ & Ref & & & \\
\hline
\end{tabular}




\begin{tabular}{|c|c|c|c|c|c|}
\hline & $>1$ & $0.621(0.465-0.829)$ & 0.001 & & \\
\hline \multirow[t]{2}{*}{ Erythrocyte sedimentation rate, $\mathrm{mm} / \mathrm{h}$} & $\leq 20$ & Ref & & & \\
\hline & $>20$ & $0.849(0.624-1.156)$ & 0.299 & & \\
\hline \multirow[t]{2}{*}{ High-sensitive C-reactive protein, mg/L } & $\leq 10$ & Ref & & & \\
\hline & $>10$ & $0.796(0.565-1.121)$ & 0.191 & & \\
\hline \multirow[t]{2}{*}{ Procalcitonin, ng/mL } & $\leq 0.5$ & Ref & & & \\
\hline & $>0.5$ & $0.704(0.371-1.333)$ & 0.281 & & \\
\hline \multirow[t]{2}{*}{ Ferritin, $\mu \mathrm{g} / \mathrm{L}$} & $\leq 400$ & Ref & & & \\
\hline & $>400$ & $0.696(0.508-0.951)$ & 0.023 & & \\
\hline \multirow[t]{2}{*}{ IL-1 $\beta, \mathrm{ng} / \mathrm{L}$} & $\leq 5$ & Ref & & & \\
\hline & $>5$ & $1.000(0.698-1.431)$ & 0.998 & & \\
\hline \multirow[t]{2}{*}{ sIL-2R, U/mL } & $\leq 710$ & Ref & & Ref & \\
\hline & $>710$ & $0.657(0.501-0.863)$ & 0.003 & $0.719(0.533-0.971)$ & 0.031 \\
\hline \multirow[t]{2}{*}{ IL-6, ng/L } & $\leq 7$ & Ref & & & \\
\hline & $>7$ & $0.947(0.714-1.257)$ & 0.708 & & \\
\hline \multirow[t]{2}{*}{ IL-8, ng/L } & $\leq 62$ & Ref & & & \\
\hline & $>62$ & $0.781(0.425-1.435)$ & 0.426 & & \\
\hline \multirow[t]{2}{*}{ IL-10, ng/L } & $\leq 9.1$ & Ref & & & \\
\hline & $>9.1$ & $0.863(0.626-1.190)$ & 0.369 & & \\
\hline \multirow[t]{2}{*}{ TNF- $\alpha, \mathrm{ng} / \mathrm{L}$} & $\leq 8.1$ & Ref & & & \\
\hline & $>8.1$ & $1.089(0.829-1.431)$ & 0.541 & & \\
\hline \multicolumn{6}{|l|}{ Systemic corticosteroids } \\
\hline \multirow[t]{3}{*}{ Prednisone-equivalent dose, mg/Kg per day } & 0 & Ref & & & \\
\hline & $<1$ & $1.008(0.759-1.339)$ & 0.957 & & \\
\hline & $\square 1$ & $0.589(0.370-0.940)$ & 0.026 & & \\
\hline \multirow[t]{2}{*}{ Intravenous immunoglobulin } & No & Ref & & & \\
\hline & Yes & $0.908(0.689-1.199)$ & 0.497 & & \\
\hline \multirow[t]{2}{*}{ Lopinavir-ritonavir } & No & Ref & & & \\
\hline & Yes & $0.919(0.687-1.230)$ & 0.570 & & \\
\hline \multirow[t]{2}{*}{ Arbidol } & No & Ref & & & \\
\hline & Yes & $0.930(0.682-1.266)$ & 0.643 & & \\
\hline \multirow[t]{2}{*}{ Oseltamivir } & No & Ref & & & \\
\hline & Yes & $1.255(0.955-1.651)$ & 0.104 & & \\
\hline
\end{tabular}

$\mathrm{HR}=$ hazard ratio. $\mathrm{CI}=$ confidence interval. $\mathrm{IL}=$ interleukin. $\mathrm{TNF}=$ tumor necrosis factor. Adjusted hazard ratios along with $95 \%$ confidence intervals were calculated by using the Cox proportional hazards regression model. 

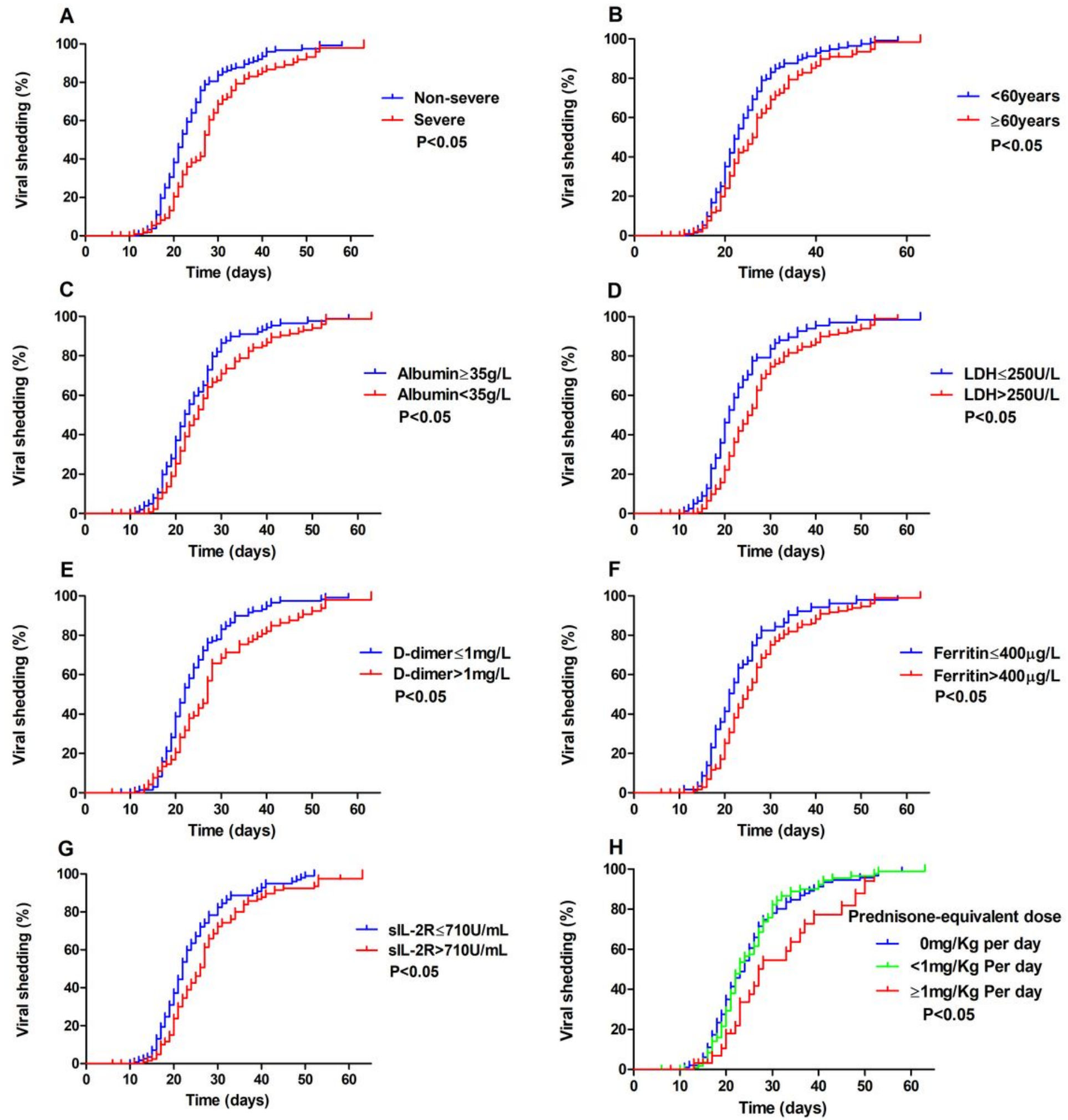

Figure 1

Kaplan-Meier curves for duration of viral shedding compared by severity (A), age (B), albumin (C), lactate dehydrogenase (D), D-dimer (E), ferritin (F), soluble interleukin-2 receptor (G) and usage of systemic corticosteroids $(\mathrm{H})$. LDHDlactate dehydrogenase; sIL-2R】 soluble interleukin-2 receptor 

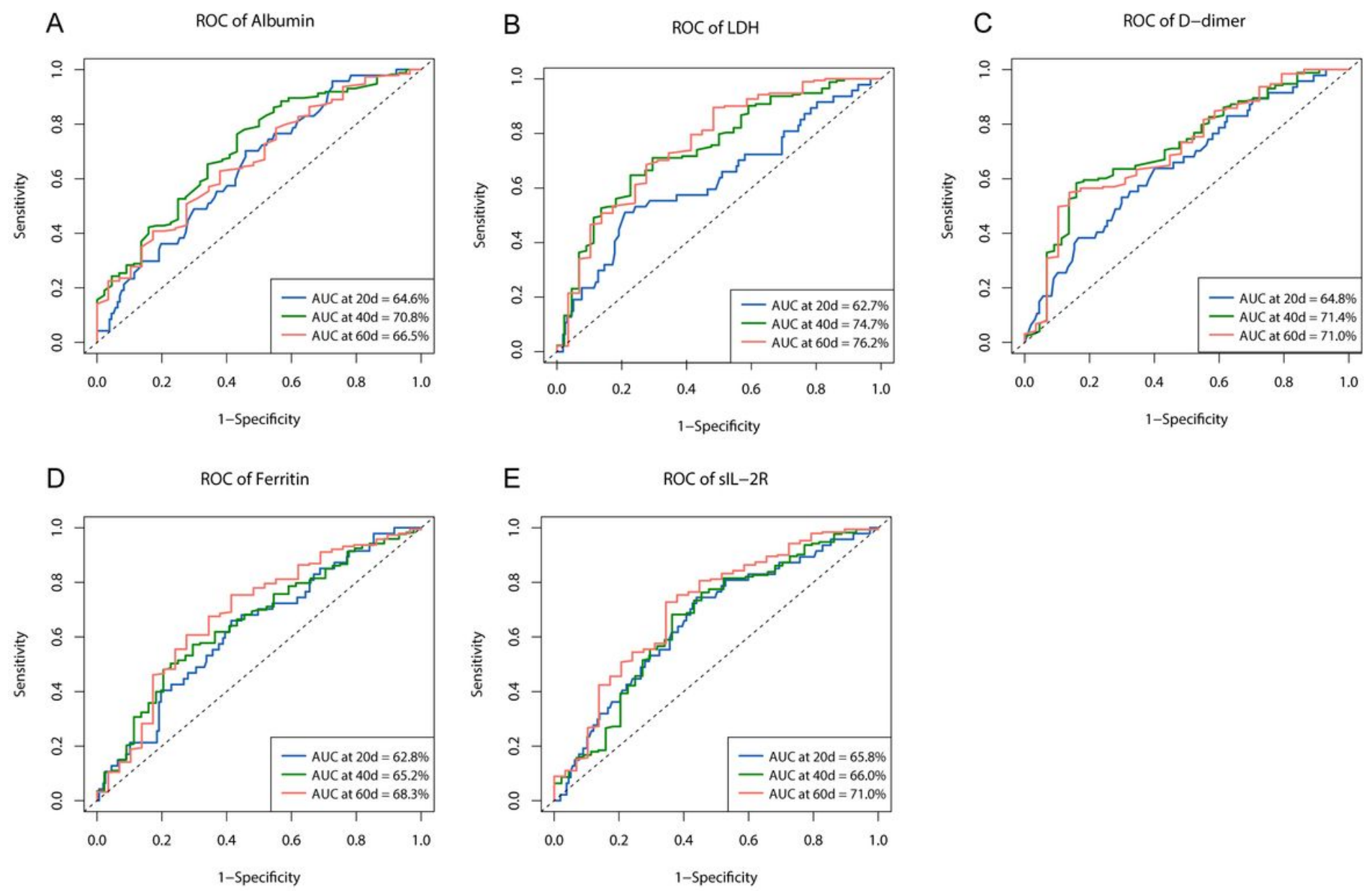

Figure 2

The time-dependent ROC curve for predictive effect of albumin (A), lactate dehydrogenase (B), D-dimer (C), ferritin (D) and soluble interleukin-2 receptor (E) at 20 days, 40 days and 60 days. LDHDlactate dehydrogenase; sIL-2R囚 soluble interleukin-2 receptor 

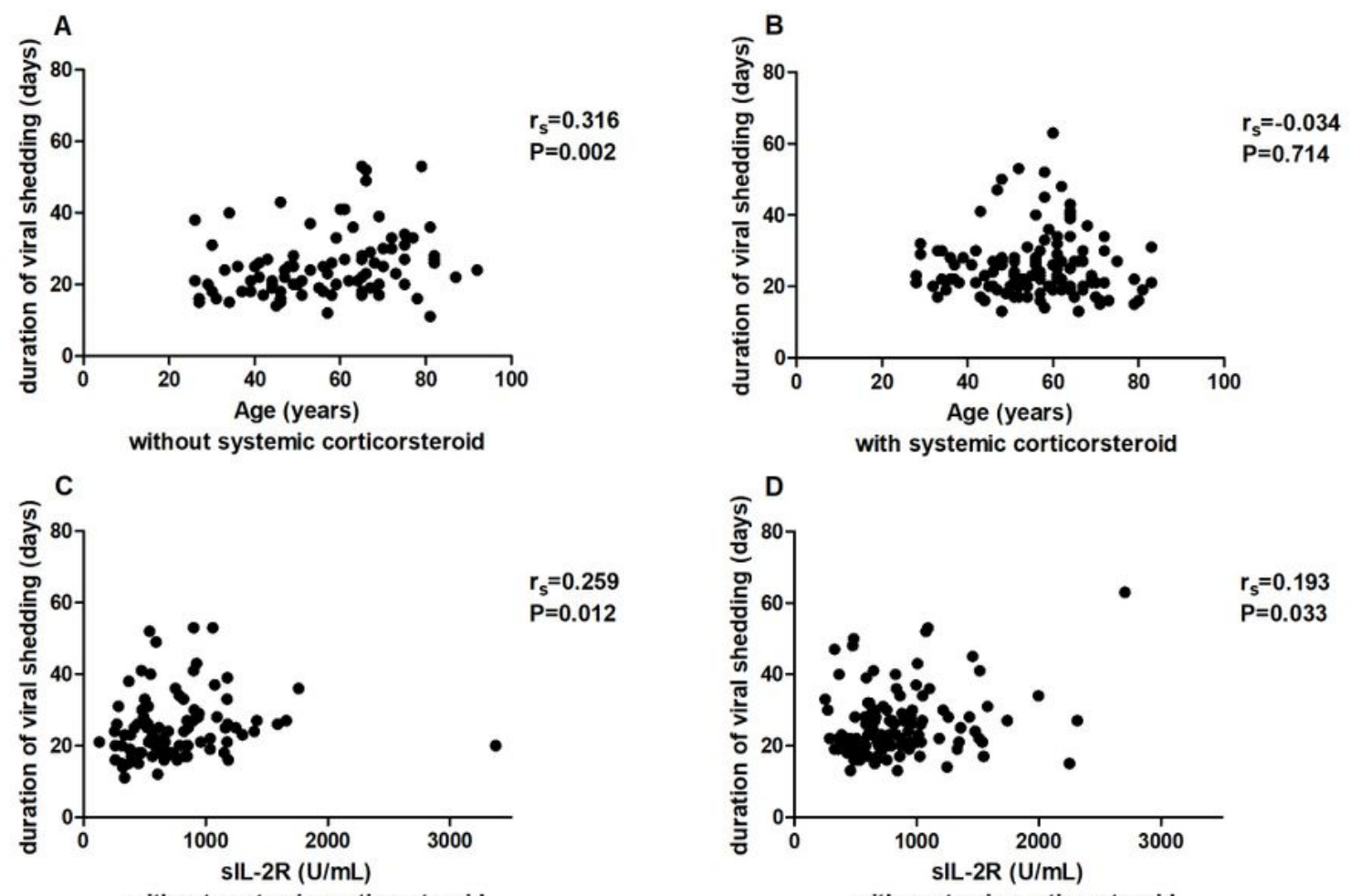

without systemic corticorsteroid
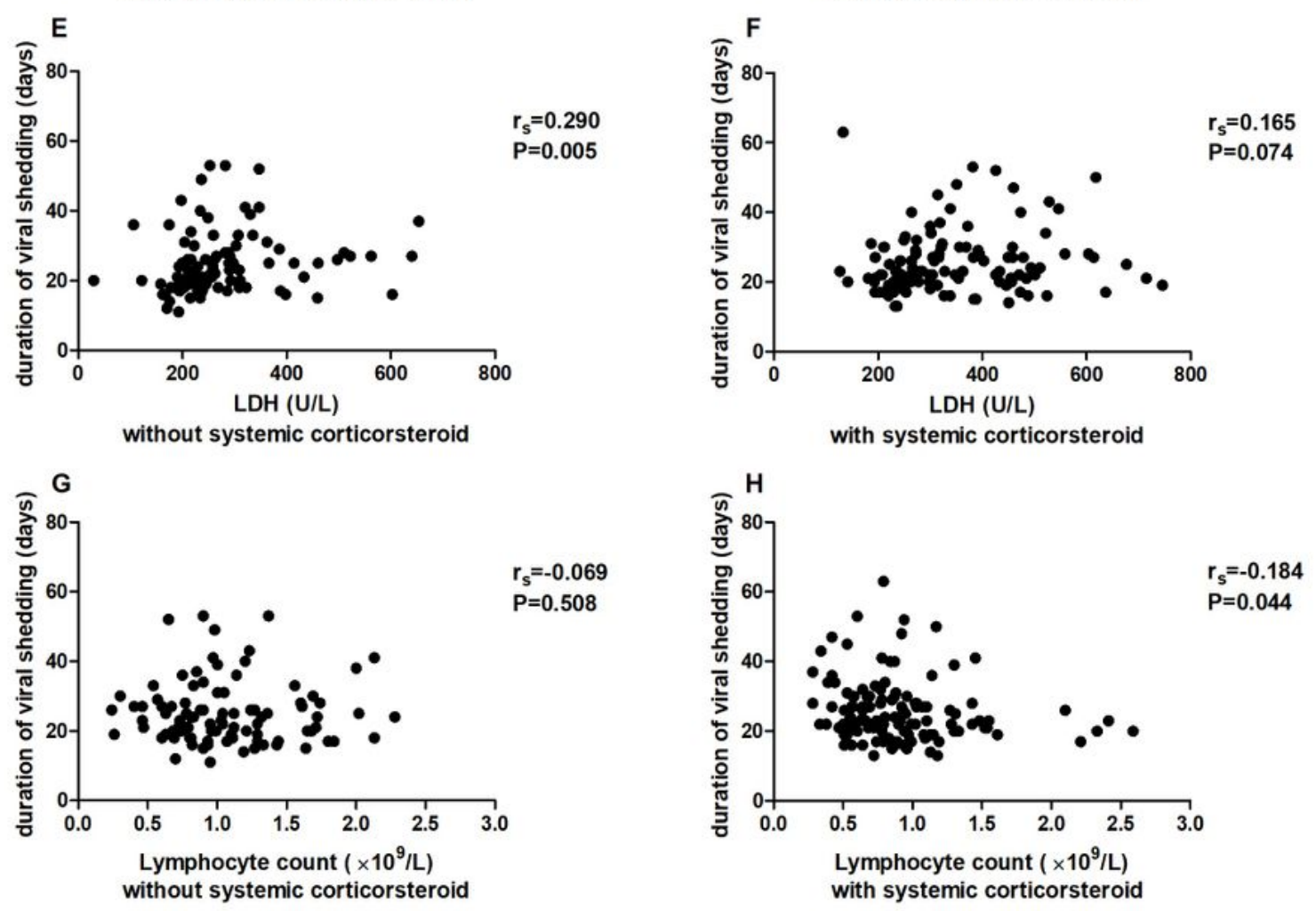

Figure 3

The correlation between duration of viral shedding and age, lactate dehydrogenase, soluble interleukin-2 receptor and lymphocyte count stratified by the usage of systemic corticosteroid. LDHDlactate dehydrogenase; sIL-2R』 soluble interleukin-2 receptor. 